\title{
Generation of tumour-specific cytotoxic T-cell clones from histocompatibility leucocyte antigen-identical siblings of patients
} with melanoma

\author{
DJ Gottlieb",', Y-C Li', I Lionello², S Tanzarella ${ }^{2}$, M Marangolo', KF Bradstock', V Russo ${ }^{3}$ and C Traversari ${ }^{2}$ \\ 'Leukaemia Research Laboratory, University of Sydney, Westmead Hospital, Sydney NSW 2145, Australia; '²Molmed, Via Olgettina 58, Milan 20132, \\ Italy; ${ }^{3}$ Cancer Immunotherapy and Gene Therapy Program, Cancer Gene Therapy Unit, Scientific Institute H San Raffaele, Via Olgettina 58, Milan 20 I 32, \\ Italy
}

\begin{abstract}
Lymphodepletion and infusion of autologous expanded tumour-infiltrating lymphocytes is effective therapy for patients with malignant melanoma. Antitumour responses are likely to be mediated by HLA class I- and II-restricted immune responses directed at tumour antigens. We assessed whether the peripheral blood of normal HLA-matched siblings of patients with melanoma could be used to generate lymphocytes with antimelanoma activity for adoptive immunotherapy after allogeneic blood or marrow transplantation. Melanoma cell lines were derived from two donors and were used to stimulate the mononuclear cells of three HLAidentical siblings. $\mathrm{CD} 4{ }^{+}$clones dominated cultures. Of these, approximately half were directly cytotoxic towards recipient melanoma cells and secreted interferon- $\gamma$ in response to tumour stimulation. More than half of the noncytotoxic clones also secreted interferon$\gamma$ after melanoma stimulation. No CD4 ${ }^{+}$clones responded to stimulation with recipient haemopoietic cells. The majority of CD8 ${ }^{+}$ clones directly lysed recipient melanoma, but did not persist in long-term culture in vitro. No crossreactivity with recipient haemopoietic cells was observed. The antigenic target of one CD4 ${ }^{+}$clone was determined to be an HLA-DRI I-restricted MAGE-3 epitope. Antigenic targets of the remaining clones were not elucidated, but appeared to be restricted through a non-HLA-DR class II molecule. We conclude that the blood of allogeneic HLA-matched sibling donors contains melanoma-reactive lymphocyte precursors directed at tumour-associated antigens. Adoptive immunotherapy with unselected or ex vivo-stimulated donor lymphocytes after allogeneic stem cell transplantation has a rational basis for the treatment of malignant melanoma.
\end{abstract}

British Journal of Cancer (2006) 95, I8I-188. doi: I0.1038/sj.bjc.6603243 www.bjcancer.com

Published online 4 July 2006

(c) 2006 Cancer Research UK

Keywords: human; tumour immunity; $T$ cells; transplantation; melanoma

Allogeneic blood or marrow transplantation is emerging as an effective treatment in some patients with solid tumours, particularly those with renal cell carcinoma (Childs et al, 1999; Childs, 2000). Other tumours including breast and ovarian cancers and germ cell tumours may also benefit from this approach (Bay et al, 2000, 2002; Pedrazzoli et al, 2002; Hanel et al, 2003; Donato et al, 2004), which is thought to exert its major antitumour effect via donor immune cells active against recipient malignancy (known as the graft-versus-tumour or GVT effect). The GVT effect makes the use of lymphocytes from HLA-identical donors preferable to the use of the patient's own lymphocytes for the purpose of generating cells for immunotherapy.

Melanoma cells express a variety of tumour antigen types that could be the target of immune responses. These include the cancer testis antigens exemplified by the MAGE family as well as differentiation antigens such as tyrosinase and melan-A/MART-1 that are expressed by normal melanocytes as well as melanoma cells (Coulie et al, 1993; Boon et al, 1994). T-lymphocytes specific

*Correspondence: Associate Professor D Gottlieb;

E-mail: david_gottlieb@wmi.usyd.edu.au

Revised 5 June 2006; accepted 6 June 2006; published online 4 July 2006 for tumour antigens can be detected at low frequency in the circulation of both melanoma sufferers and normal individuals (Lee et al, 1999; Valmori et al, 2000; Pittet et al, 2001). The use of blood from HLA-identical donors offers two major advantages. Patients with melanoma may have deficient immune responses owing to advanced malignancy itself or to the effects of chemoradiotherapy. In addition, the expression of polymorphic tissue antigens by melanoma cells offers additional antigens that can be targeted by allogeneic lymphocytes.

When autologous melanoma-infiltrating lymphocytes expanded in vitro are infused into melanoma sufferers following lymphodepleting chemotherapy, a $50 \%$ rate of objective response has been observed in patients with metastatic melanoma (Dudley et al, 2002, 2005). Tumour targets have included the products of MAGE, HLA, tumour suppressor and other polymorphic genes (Robbins et al, 2002; Huang et al, 2004; Zhou et al, 2005). However, the process of cell generation requires the use of lymphocytes isolated from tumour biopsies and is labour intensive and impractical for routine clinical purposes. To take advantage of the additional alloreactivty provided by polymorphic minor histocompatibility antigens and to utilise the immunocompetent systems of normal donors, we generated melanoma cell lines from two patients with metastatic melanoma and used them to stimulate lymphocytes 
from the peripheral blood of their HLA-identical siblings. We aimed to determine the ease with which melanoma-reactive clones could be generated and to characterise the clones. We intended to determine the feasibility of infusing in vitro expanded melanomareactive allogeneic lymphocytes following reduced-intensity lymphodepleting chemotherapy and establishment of allogeneic haemopoietic chimerism in patients with melanoma.

\section{MATERIALS AND METHODS}

\section{Cell lines}

Approval from our Institutional Ethics Committee was granted and informed consent from donors was obtained before collection of any biological samples. Melanoma samples were obtained from surgical biopsies of metastatic lesions in two patients WMPG (tissue type HLA-A1, B44, 49, DRB1 11, 12) and WMMH (tissue type HLA-A3, 24, B7, 35, DRB1 13, 15). Biopsies of melanoma lesions from patients were washed in sterile PBS, cut into small pieces and digested with trypsin-EDTA (Invitrogen, Carlsbad, CA, USA) until all tumour aggregates were disassociated. The cells harvested were centrifuged and cultured in RPMI media $+10 \%$ FCS at $37^{\circ} \mathrm{C}$ in a humidified atmosphere containing $5 \% \mathrm{CO}_{2}$. Nonadherent cells were discarded and adherent cells were passaged using trypsin-EDTA. Cell lines had the appearance of large adherent cells typical of malignant melanoma cells and were characterised by reverse transcriptase-polymerase chain reaction (RT-PCR) for melanoma antigens (see Results). The melanoma lines ET1 and LB33, and the lymphoblastoid cell line (LCL) LG2EBV were kindly provided by Professor T Boon (Ludwig Institute for Cancer Research, Brussels, Belgium). The melanoma lines MDTC, OI-TC, GRA and the HLA-DR11 + BOR-EBV were a kind gift of Dr MP Protti (Scientific Institute H San Raffaele, Milan, Italy). Me18732 was kindly provided by Dr Parmiani (Istituto Nazionale dei Tumori, Milan, Italy). Peripheral blood mononuclear cells (PBMCs) were isolated from patients or their HLA-A-, -B-, -DRB1identical donors by Lymphoprep (Nycomed, Oslo, Norway) gradients. Activated T cells were obtained by cultivation of PBMC, in the presence of $1 \mu \mathrm{g} \mathrm{ml}^{-1}$ of PHA (Boehringer Mannheim, Mannheim, Germany) and $100 \mathrm{U} \mathrm{ml}^{-1}$ r-hu-IL-2 (Chiron, Milan, Italy). B-lymphoblastoid cell lines were derived by transformation of peripheral blood B-lymphocytes with the B95-8 strain of EBV, obtained from the Department of Virology, Institute for Clinical Pathology and Medical Research, Westmead Hospital. Bone marrow fibroblasts were isolated by adherence from marrow aspirates and were cultured in RPMI $+10 \%$ FCS, passaged at confluency and reseeded at $10 \%$ confluency.

\section{Flow cytometry}

Antibodies to human CD3, CD4, CD8, CD13, CD19, CD56, CD80, CD86, CD62L, interferon- $\gamma$ and IL-4 were purchased from $\mathrm{BD}$ Biosciences (San Jose, CA, USA). W6/32 (anti-HLA class I) was purchased from Sigma-Aldrich (St Louis, MO, USA). Flow cytometry was carried out on a FACSCalibur flow cytometer (BD Biosciences, San Jose, CA, USA) and analysed using CellQuest software. To label intracellular antigens including cytokines, cells were first fixed by incubation in $4 \%$ paraformadehyde. After washing, cells were incubated in ICPerm (Biosource, Nivelles, Belgium) and were labelled with primary antibodies and washed in PBS. If the primary antibody was not conjugated to fluorochromes, fluorochrome-conjugated secondary antibody was added and cells were incubated before washing and analysing on the flow cytometer.

\section{In vitro induction of tumour-specific effectors}

Autologous mixed lymphocyte tumour cell cultures (MLTCs) were established as described previously (Van den Eynde et al, 1989) using irradiated autologous tumour in the presence of $10 \mathrm{U} \mathrm{ml}^{-1}$ IL-2 (Chiron, Milan, Italy) and $5 \mathrm{ng} \mathrm{ml}^{-1}$ IL-7 (Genzyme Corp., Cambridge, MA, USA). Cultures were maintained in IMDM $+10 \%$ pooled human $\mathrm{AB}$ serum supplemented with $0.55 \mathrm{~mm} \mathrm{~L}$-arginine, $0.24 \mathrm{~mm}$ L-asparagine and $1.5 \mathrm{~mm} \mathrm{~L}$-glutamine, $50 \mathrm{U} \mathrm{ml}^{-1}$ penicillin and $50 \mu \mathrm{g} \mathrm{ml}^{-1}$ streptomycin. Lymphocytes were stimulated weekly and tested in cytotoxicity or cytokine release assays after three stimulations. On day 21 , lymphocytes from the culture were cloned by limiting dilution and maintained in culture as described previously (Traversari et al, 1989). In brief, lymphocytes from MLTCs were counted and seeded in 96-well plates at a ratio of 0.3 cells well $^{-1}$. To each well, 500 melanoma cells ( $\gamma$-irradiated to $90 \mathrm{~Gy}), \quad 30000$ EBV-transformed feeder lymphoblastoid cells (irradiated to $90 \mathrm{~Gy}$ ) and IL-2 (final concentration $50 \mathrm{U} \mathrm{ml}^{-1}$ ) were added in a total culture volume of $200 \mu \mathrm{lwell}^{-1}$. Half of the media and IL-2 were replaced every 3-4 days, and fresh irradiated melanoma cells and EBV-LCL feeder cells were added weekly as above. After 3-4 weeks, wells were examined by light microscopy for outgrowth of lymphocytes. Positive wells were maintained at $10^{5}$ cells well $^{-1}$ until expanded sufficiently for testing.

\section{Cytotoxicity assay}

The lytic activity of CTLs was tested in a classical chromium release assay (Gottlieb et al, 1989), in the presence of 30:1 excess of cold K562 cells. For blocking assays, the effector cells were preincubated with Ab specific for CD3 (OKT3: Orthoclone, Milan, Italy), CD4, CD8 or alternatively target cells were preincubated with anti-MHC class I (W6/32) and anti-HLA-DR (L243) Abs $30 \mathrm{~min}$ at room temperature. Effector and target cells were added in 96-well microplates at a fixed $\mathrm{E}: \mathrm{T}$ ratio to evaluate the lytic activity as ${ }^{51} \mathrm{Cr}$ release after $4 \mathrm{~h}$.

\section{Cytokine secretion assay}

Responder cells $\left(1 \times 10^{5}\right)$ at day 5 after stimulation and stimulator cells $\left(3 \times 10^{5}\right)$ were mixed in $150 \mu$ l of IMDM $10 \%$ human serum supplemented with $25 \mathrm{U} \mathrm{ml}^{-1} \mathrm{IL}-2$. After $24 \mathrm{~h}$ at $37^{\circ} \mathrm{C}, 100 \mu \mathrm{l}$ of supernatant were harvested, and interferon- $\gamma$ concentration was measured using an interferon- $\gamma$ ELISA kit (BD Biosciences Pharmingen, San Diego, CA, USA) according to the manufacturer's recommendations. Blocking experiments were performed as described above.

\section{RESULTS}

\section{Characterisation of melanoma cell lines}

Cell lines WMPG and WMMH grew as adherent cells with the typical morphological appearance of melanoma cells. By PCR, WMPG was shown to express MAGE-2, MAGE-3, MAGE-6, Melan-A, tyrosinase and gp100, whereas WMMH expressed MAGE-2, MAGE-3, tyrosinase and Melan-A (Figure 1). Both WMPG and WMMH expressed high levels of HLA class I and II, ICAM-1 and LFA-3 (Figure 2). However, neither cell line expressed B7.1 or B7.2, the principal costimulatory molecules required for the activation of naive $\mathrm{T}$ cells (Figure 2). Additionally, neither cell line expressed cell surface antigens of T, B or natural killer origin (data not shown).

\section{Generation and characterisation of T-cell clones}

Mixed lymphocyte tumour cell cultures were established using WMPG melanoma cells and effectors from his HLA-identical sibling, and from WMMH and effectors from each of two HLAidentical siblings. After limiting dilution cloning, a total of 49 lymphocyte clones was obtained from 1560 seeded wells. Only two out of a total of 49 clones were $\mathrm{CD} 8{ }^{+}$, the remainder being $\mathrm{CD} 4{ }^{+}$. 


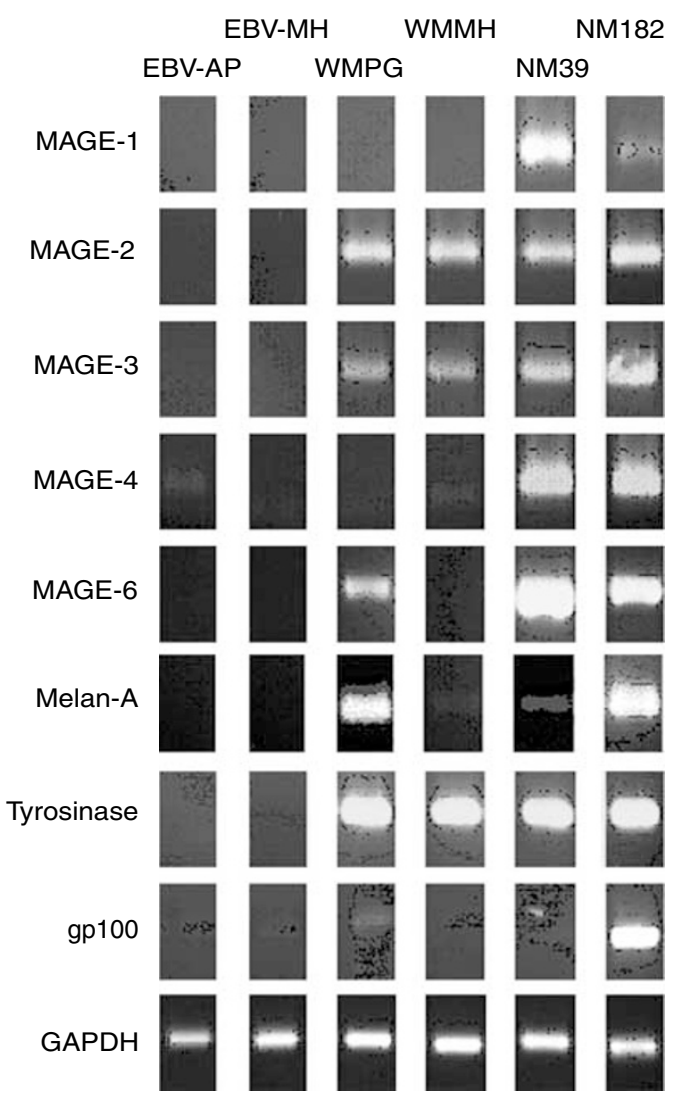

Figure I Expression of melanoma antigens by WMPG and WMMH. Reverse transcriptase-polymerase chain reaction was used to assess expression of a panel of common melanoma antigens by WMPG and WMMH. RNA was extracted from WMPG and WMMH, reversetranscribed and amplified with primers that anneal to mRNAs of melanoma antigens. Reverse transcriptase-polymerase chain reaction products of two EBV-LCL cell lines (EBV-AP and EBV-MH) and two other melanoma cell lines (NM39 and NMI82) were included as negative and positive controls, respectively. Amplification of GAPDH was shown as loading control. Bands of sizes corresponding to amplification of mRNAs (instead of genomic DNA) were shown.

To derive $\mathrm{CD}^{+}$T-cell clones for further study, MLTCs were sorted into $>99 \%$ pure $\mathrm{CD}^{+}$and $\mathrm{CD}^{+}$fractions and $\mathrm{CD} 8{ }^{+}$ $\mathrm{T}$ cells were then cloned by limiting dilution. From a total of 960 seeded wells, $47 \mathrm{CD}^{+}{ }^{+}$and $65 \mathrm{CD}^{+}$clones were obtained (Table 1). The phenotype of clones was verified periodically throughout this study. The $\mathrm{CD} 8^{+}$clones expanded during the limiting dilution process, but none was able to persist and expand in culture for more than 2 months after limiting dilution despite coculture with OKT3 or irradiated allogeneic PBMC from healthy donors or EBV-transformed feeder cells (LG2-EBV). This limited their functional characterisation. On the other hand, a number of $\mathrm{CD}^{+}{ }^{+} \mathrm{T}$-cell clones were able to survive and expand for greater than 4 months in culture, enabling their further characterisation in subsequent experiments.

For a number of $\mathrm{CD}^{+} \mathrm{T}$-cell clones, cytotoxicity against recipient melanoma cells was demonstrated in ${ }^{51}$ Cr-release cytotoxicity assays. Data from representative clones are shown in Figure 3A. Clones QB10 and QF10 were generated by limiting dilution from $\mathrm{CD}^{+}{ }^{+}$-sorted MLTC of the WMPG donor/stimulator pair. Clone KP8S4 was derived by limiting dilution from $\mathrm{CD} 8^{+}$sorted MLTC of the WMMH donor/stimulator pair. Clones QB10 and QF10 killed recipient melanoma WMPG cells but did not show cytotoxicity against LG2-EBV feeder cells nor against PHA blasts derived from the originator of the WMPG line, suggesting that clones QB10 and QF10 recognised an antigen expressed by melanoma rather than a minor histocompatibility antigen expressed by tumour cells. This pattern of cytotoxicity was observed in 38 out of $45 \mathrm{CD}^{+}$T-cell clones raised from the donor against WMPG. Seven out of $45 \mathrm{CD} 8^{+}$clones showed no cytotoxicity against either WMPG or EBV feeder cells. As shown in Figure 3, KP8S4 killed recipient melanoma WMMH but not LG2EBV feeder cells nor EBV-transformed cells from the originator of the WMMH line, suggesting that KP8S4 also recognised an antigen expressed by WMMH melanoma but not a minor histocompatibility antigen expressed by donor $\mathrm{MH}$. Only two $\mathrm{CD}^{+}{ }^{+} \mathrm{T}$-cell clones derived from WMMH-stimulated cultures (including KP8S4) could be expanded for testing. As the aim of the study was only to analyse the characteristics of clones generated from HLA-identical siblings, no attempt was made to expand clones to numbers that might be required for therapeutic purposes.

In contrast to $\mathrm{CD} 8{ }^{+}$clones, most $\mathrm{CD} 4{ }^{+} \mathrm{T}$-cell clones were able to survive and expand in culture, enabling their further characterisation. Recognition of WMPG by the lymphocytes was assessed in ${ }^{51} \mathrm{Cr}$-release cytotoxicity assays. Results from three representative clones are shown in Figure 3B. CD4 ${ }^{+}$clones DB5 and MC5 killed the recipient melanoma cell line WMPG specifically and not recipient PHA blasts or the LG2-EBV feeder cell line. However, another clone JC8 failed to lyse the original WMPG. Of the $14 \mathrm{CD}^{+}$clones characterised, four clones displayed cytotoxicity patterns similar to clones DB5 and MC5. Another three clones killed WMPG, but cytotoxicity assays were not performed against PHA blasts owing to the clones dying in culture. The remaining seven $\mathrm{CD}^{+}$clones did not kill WMPG. A total of $25 \mathrm{CD}^{+}{ }^{+}$T-cell clones were derived from the two HLA-identical siblings of the WMMH line. These clones were tested against WMMH targets in ${ }^{51} \mathrm{Cr}$-release cytotoxicity assays (Figure 4A). Two patterns of cytotoxicity were observed. Half of the $\mathrm{CD}^{+}{ }^{+}$clones derived exhibited cytotoxicity directly against recipient melanoma cells without killing a WMMH-derived EBV cell line, implying the clones did not recognise a minor histocompatibility antigen. The remaining clones did not kill the WMMH melanoma line or EBV-transformed recipient or feeder cells. All clones that were cytotoxic secreted interferon- $\gamma$ in response to stimulation with WMMH (Figure 4B). However, four of the six noncytotoxic clones also released interferon- $\gamma$ in response to WMMH. No clones tested secreted interferon- $\gamma$ in response to stimulation with WMMH EBV-transformed cells or LG2-EBV feeder cells, indicating that no clones recognised minor histocompatibility antigens expressed by the tumour cells or the patient's EBV-transformed cells.

\section{Characterisation of target epitopes of $\mathrm{CD}^{+}$T-cell clones}

An attempt was made to identify the antigen(s) recognised by $\mathrm{CD} 4{ }^{+}$clones. MAGE-3-derived peptides presented by HLA-DR11 and recognised by $\mathrm{CD}^{+}$T-lymphocytes have previously been identified (Hahn et al, 1995). To test if any of the clones generated from the HLA-identical donor of the WMPG patient (that expressed HLA-DR11) recognised MAGE-3 peptides in association with HLA-DR11, $\mathrm{CD} 4^{+}$clones were used as effectors in cytotoxicity assays against an HLA-DR11 + EBV-LCL engineered to express MAGE-3. One of seven clones tested (clone PR3) was cytotoxic against the MAGE-3 transfectant, but not the vectoronly-transfected line (Figure 5A). To validate this result, clone PR3 was tested for its ability to secrete interferon- $\gamma$ in response to stimulation with six melanoma cell lines (four HLA-DR11 +, two HLA-DR11-). Clone PR3 secreted interferon- $\gamma$ in response to WMPG, the MAGE-3-transfected HLA-DR11 + EBV-transformed cell line and three of four HLA-DR11 + melanoma cell lines, but did not secrete interferon- $\gamma$ after stimulation with either of the HLA-DR11- melanoma lines or after stimulation with an HLADR11 + line (LB33) with low HLA-DR expression (Figure 5B and 
A a

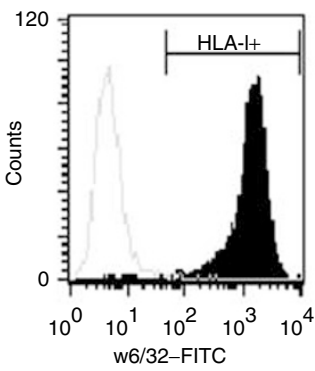

d

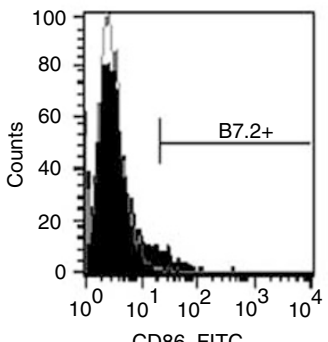

B a
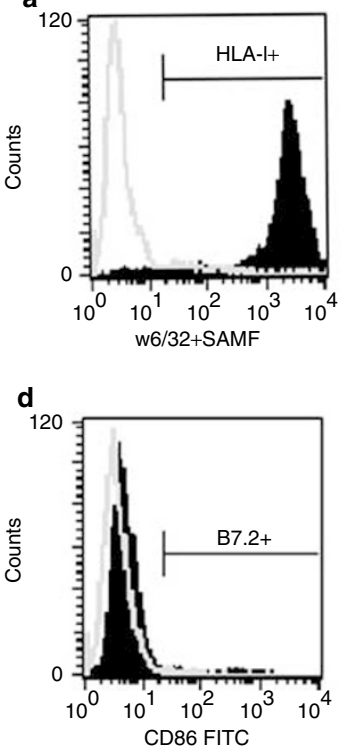

b

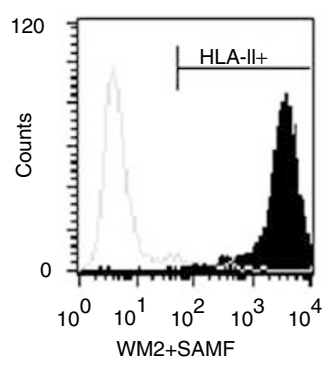

e

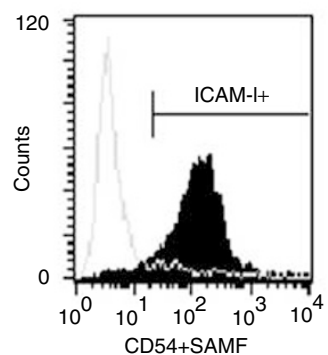

b

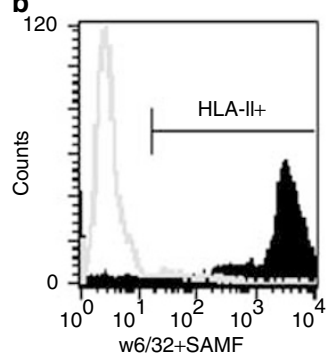

e

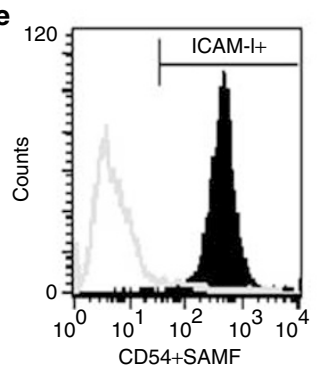

C

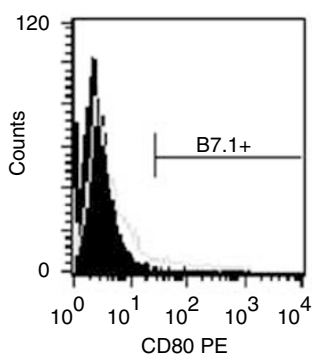

f

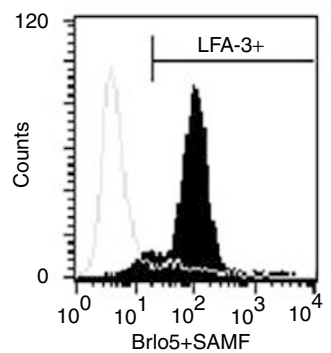

$c_{100}$
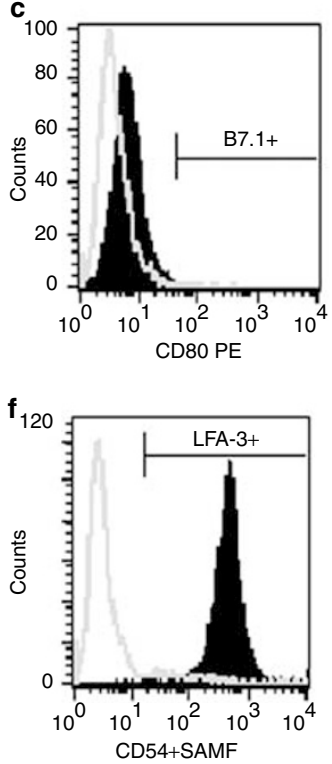

Figure 2 Expression of HLA, costimulatory molecules and adhesion molecules by WMPG $(\mathbf{A})$ and WMMH (B). Cells were stained with antibodies specific for (a): HLA class I; (b): HLA class II; (c): B7.I; (d): B7.2; (e): ICAM-I and (f): LFA-3 and assessed by flow cytometry. Grey lines represent staining with isotype control antibodies, and black lines staining with the indicated antibodies.

Table I Number of CD4+ and CD8+ clones derived from (a) WMPGJG donor pair, (b) WMMH-AP donor pair and (c) WMMH-KP donor pair

\begin{tabular}{lcc}
\hline & $\begin{array}{c}\text { CD4+ } \\
\text { (recognising } \\
\text { stimulator) }\end{array}$ & $\begin{array}{c}\text { CD8+ } \\
\text { (recognising } \\
\text { stimulator) }\end{array}$ \\
\hline (a) WMPG-JG & $22(7 / 10 / 5)$ & $45(38 / 6 / 1)$ \\
(b) WMMH-AP & $13(6 / 1 / 6)$ & $6(0 / 0 / 6)$ \\
(c) WMMH-KP & $12(5 / 1 / 6)$ & $14(2 / 0 / 12)$ \\
\hline
\end{tabular}

Recognition of stimulator cell was determined either by Cr-release cytotoxicity assay or interferon- $\gamma$ release as described in Materials and Methods. Numbers in brackets show the number of clones recognising, not recognising and not tested against the original stimulator cells, respectively. data not shown). The remaining clones failed to respond to either MAGE-3-transduced or -untransduced HLA-DR11 + EBV lines. $\mathrm{CD}^{+}{ }^{+}$clone APLD2 isolated from one of the HLA-identical donors of the originator of the WMMH line killed the WMMH cell line but not EBV-transformed cell lines from the WMMH donor (see above). An attempt was made to identify the class II restriction element by inhibiting the cytotoxicity with the anti-HLA-DR monoclonal antibody L243. The activity of the APLD2 clone was inhibited by anti-CD3 and anti-CD4 Abs; however, no inhibition of cytotoxicity or interferon- $\gamma$ release could be obtained implying that the restriction element must be another (non-HLA-DR) class II determinant (Figure 6). A donor EBV-transformed cell line was generated and transfected with retroviral constructs containing 
A

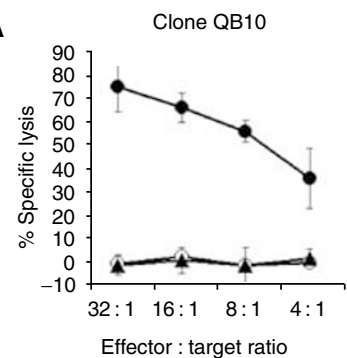

B

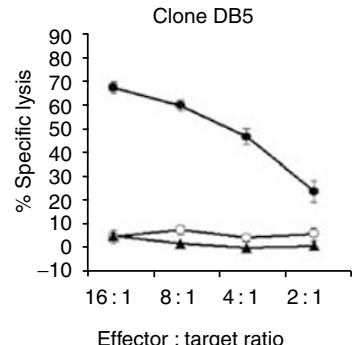

Clone QF10
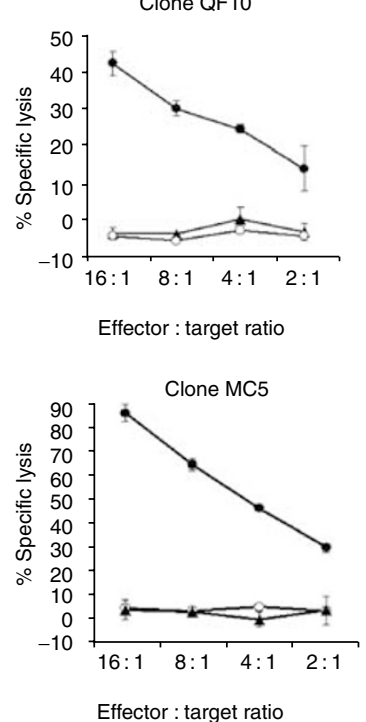

Clone KP8S4

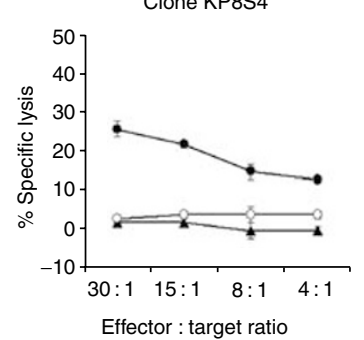

Clone JC8

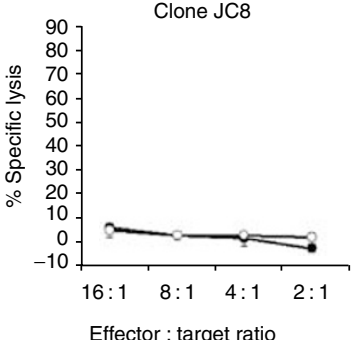

Figure 3 Cytotoxicity of T-cell clones. CD8 ${ }^{+}$T-cell clones against recipient melanoma cells. $(\mathbf{A})$ CD8 ${ }^{+}{ }^{T}$-cell clones QBI0 and QFI0 from the WMPG donor-recipient pair, and clone KP8S4 from the WMMH donor-recipient pair were used as effectors against recipient melanoma cells (solid dots), the feeder cells LG2-EBV (open circles) and cell lines of recipient origin (PHA-PG for QBIO and QFI0, EBV-MH for KP8S4; solid triangles). Error bars represent 95\% confidence interval $(\mathrm{Cl})$ calculated from triplicates. (B) CD4 ${ }^{+}$T-cell clones DB5, MC5 and JC8 were used as effectors in cytotoxicity assays against WMPG (solid dots), the feeder cells LG2-EBV (open circles) and PHA blasts from WMPG (solid triangles). Error bars represent $95 \%$ Cls calculated from triplicates.

A

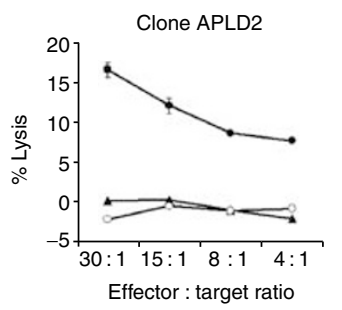

B

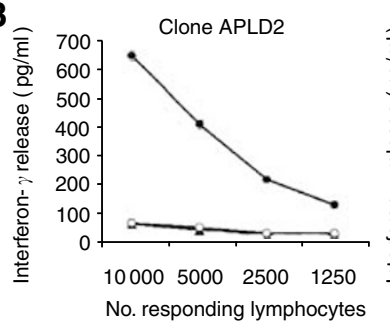

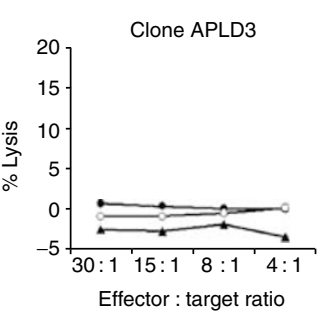

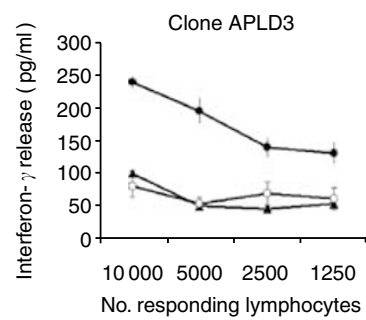

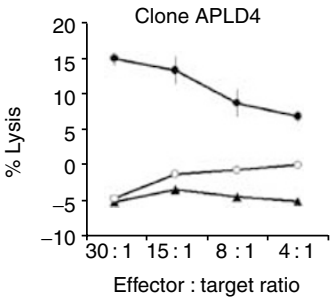

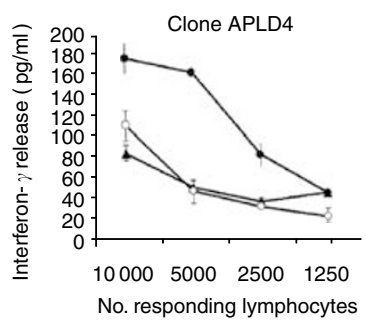

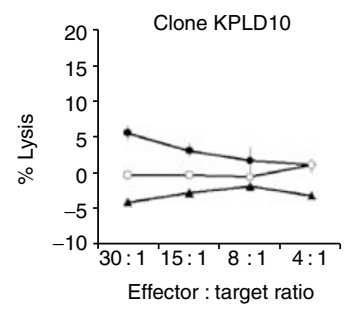

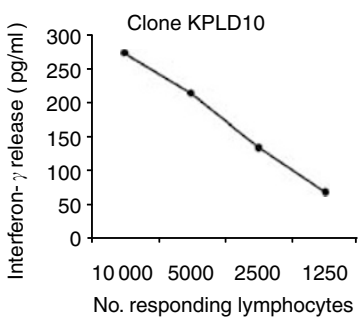

Figure 4 (A) Cytotoxicity of CD4 ${ }^{+}$clones raised from WMMH donors. Clones APLD2, APLD3, APLD4 and KPLDI0 were used as effectors against recipient melanoma (solid dots), recipient-derived EBV-LCL (solid triangles) and the feeder cells LG2-EBV (open circles) in cytotoxicity assays. Error bars represent $95 \% \mathrm{Cl}$ calculated from triplicates. (B) Interferon- $\gamma$ release by CD4 ${ }^{+}$clones raised from WMMH donors. Clones APLD2, APLD3, APLD4 and KPLDIO from donors AP and KP were used as effectors against targets consisting of recipient melanoma WMMH (solid dots), recipient-derived EBV-LCL (EBV-MH; solid triangles) and the feeder cells LG2-EBV in a cytokine secretion assay. Error bars represent 95\% Cl calculated from triplicates. Results were representative of at least two experiments.

MAGE-2, MAGE-3 or Melan-A. None of the eight clones tested secreted interferon- $\gamma$ against any of the melanoma antigentransfected cell lines (data not shown).

\section{DISCUSSION}

Infusion of autologous in vitro expanded tumour-infiltrating lymphocytes into lymphodepleted hosts suffering from melanoma is associated with high rates of disease response in patients with advanced disease (Dudley et al, 2005). The use of allogeneic donors as a source of immune system cells could have benefits, in particular the recognition of minor histocompatibility antigens on tumour cells by allogeneic donor lymphocytes and the potential for improved functional immune responses using cells from noncompromised healthy donors. In this work, we assessed the potential for HLA-A-, -B- and -DR-identical sibling donors to act as a source of melanoma-reactive lymphocytes that could exert a GVT effect if infused after allogeneic stem cell transplant. Both 
A

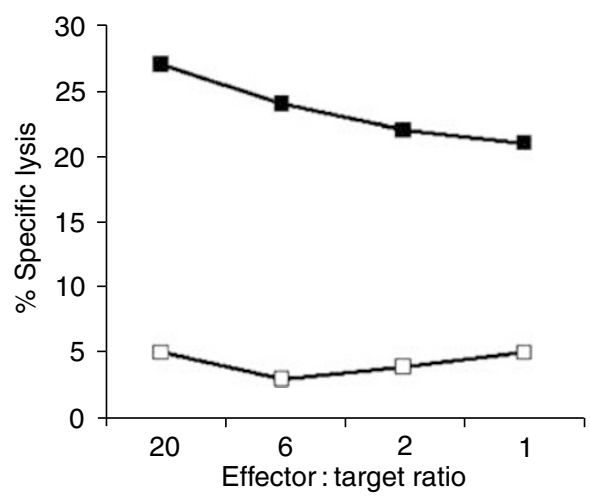

B

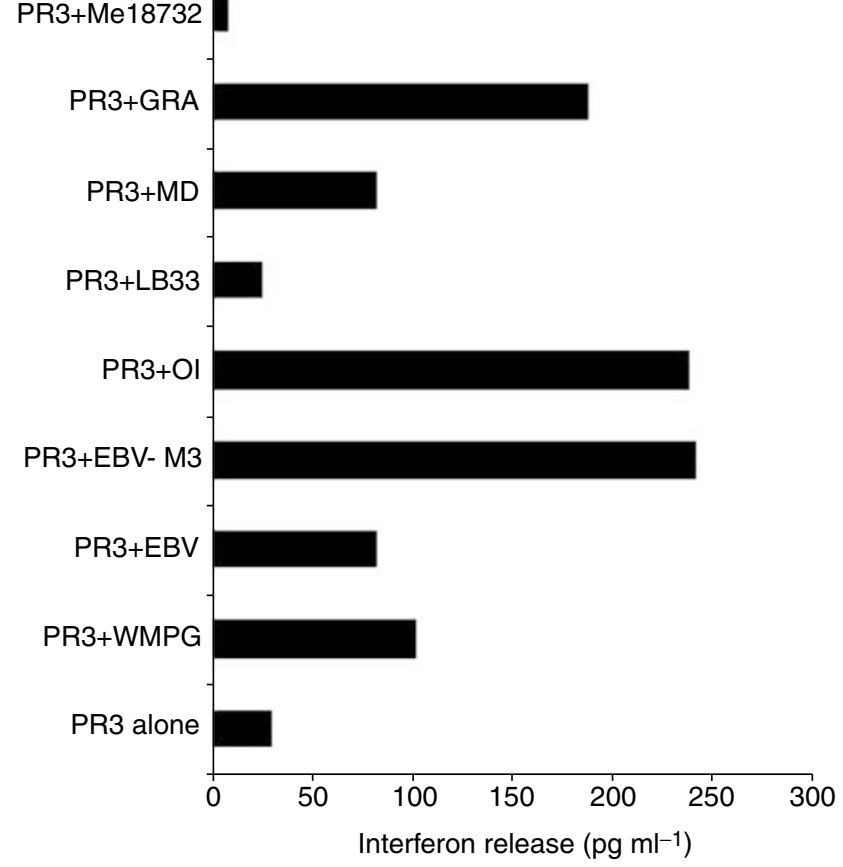

Figure 5 Characterisation of clone PR3. (A) Specific lysis by clone PR3 against an MAGE-3-transfected (closed squares) or a vector-onlytransfected (open squares) HLA-DRII + EBV-transformed cell line. (B) Interferon- $\gamma$ release by clone PR3. Interferon- $\gamma$ release by PR3 cells was measured following culture with HLA-DRII- melanoma cells (ET-I, Mel8732), HLA DRII + melanoma cells (GRA, MD, LB33, Ol and WMPG) and an HLA DRII + EBV-transformed cell line either controltransfected (EBV) or transfected with MAGE-3 (EBV-M3). Interferon- $\gamma$ release by the stimulating cells was subtracted.

$\mathrm{CD}^{+}$and $\mathrm{CD}^{+}$clones, particularly the former, could be generated from the blood of HLA-identical normal sibling donors of melanoma sufferers. All previous reports of melanoma-reactive cytotoxic cells raised from normal donors, including the only other study using HLA-matched identical donors (Kurokawa et al, 2002), have identified dominant MHC class I-restricted responses in cultured cells. (Kurokawa et al, 2002; Glazyrin et al, 2003; Nolte et al, 2003). Our report is the first to demonstrate the generation of predominantly $\mathrm{CD}^{+}{ }^{+}$melanoma-reactive clones, many interferon$\gamma$ secreting, from normal donors.

We generated cell lines from biopsies of metastatic lesions of two patients with melanoma. These lines had the morphological and culture features of neoplastic cells and expressed antigens
A

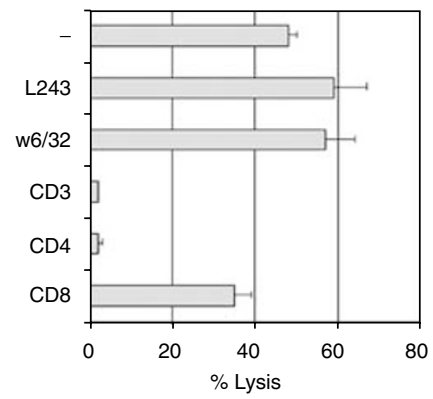

B
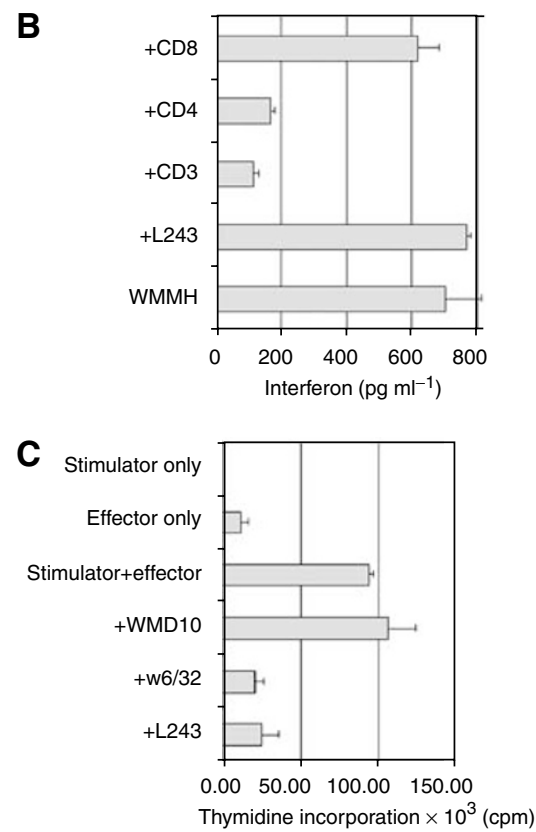

Figure 6 Inhibition of APLD2 cytotoxicity and interferon- release. $(\mathbf{A})$ L243, W6/32, OKT3, anti-CD4 and anti-CD8 Abs were added to 4-h ${ }^{51} \mathrm{Cr}$ release cytotoxicity assays using APLD2 as effector and WMMH as targets. (B) The same Abs were also used to block overnight interferon- release by APLD2 against WMMH. (C) To test the validity of the Ab preparations, the Abs were used to block 5-day one-way mixed lymphocyte reactions using PBMCs from random allogeneic normal donors. Cytotoxicity assays were performed in triplicates, and error bars represent $95 \% \mathrm{Cl}$ of triplicates. Percentage-specific lysis at an effector:target ratio of $50: 1$ is shown. Dose-responses using lower effector: target ratios were observed and are not shown. Interferon- $\gamma$ release assay was performed in duplicate and error bars represent range of duplicates. ${ }^{3} \mathrm{H}$-thymidine incorporation assay to measure lymphocyte proliferation was performed in quadruplicates and error bars represent $95 \%$ Cls. All results representative of two experiments.

typical of melanoma cells. Using PBL of HLA-identical siblings as responder cells, melanoma-reactive effectors were isolated from three HLA-identical siblings of the two melanoma cell line originators. Clones were obtained from MLTCs with an overall cloning efficiency of approximately $3 \%$. Both $\mathrm{CD} 4^{+}$and $\mathrm{CD} 8{ }^{+}$ clones were melanoma reactive, but $\mathrm{CD} 4{ }^{+}$clones dominated the cultures. $\mathrm{CD}^{+}$clones derived after cell sorting of bulk cultures failed to persist for longer than 2 months in vitro. Despite this, some $\mathrm{CD}^{+}$clones efficiently lysed parental melanoma lines. In cytokine release assays, $\mathrm{CD} 8{ }^{+}$clones released interferon- $\gamma$ but not IL-4 (data not shown) in response to stimulation with melanoma lines consistent with the acquisition of a Tc1 phenotype.

The reason for the dominance of $\mathrm{CD}^{+}$clones and the failure to propagate long-term $\mathrm{CD} 8{ }^{+}$clones from these cultures is unclear. Possibilities include the specific antigen stimulus (Glazyrin et al, 
2003), our use of whole tumour cells and the class I and II HLA matching in this allogeneic system. Although the original experiments cloning melanoma-reactive $\mathrm{CD} 8{ }^{+} \mathrm{CTL}$ were also performed with whole autologous tumour cells (Herin et al, 1987), others have also reported difficulty isolating $\mathrm{CD} 8{ }^{+} \mathrm{CTL}$ clones following this type of stimulation (Takahashi et al, 1995). In one study that generated tumour-specific $\mathrm{CD}^{+}$cytotoxic $\mathrm{T}$ cells from allogeneic donors, MLTCs were initiated with a highly purified population of $\mathrm{CD}^{+}$donor lymphocytes potentially underestimating the role of $\mathrm{CD}^{+}$clones in the immune response. (Dorrschuck et al, 2004). Our data are the first to document the results of cloning MHC class I and II HLA-matched allogeneic effector cells stimulated with whole tumour cells and are in line with previous observations made using autologous MLTC (Takahashi et al, 1995).

Approximately half of the $\mathrm{CD} 4{ }^{+}$clones were weakly cytotoxic against the melanoma cell line used for stimulation. More than half of the remaining noncytotoxic $\mathrm{CD} 4{ }^{+}$clones released interferon- $\gamma$ on exposure to the melanoma line. Several other studies have reported isolation of HLA class II-restricted melanoma-specific $\mathrm{CD} 4{ }^{+}$CTLs, including clones recognising MAGE-3, NY-ESO1 and tyrosinase epitopes (Kobayashi et al, 1998; Chaux et al, 1999; Manici et al, 1999; Zarour et al, 2000). We isolated a CD4 ${ }^{+} \mathrm{HLA}-$ DR11-restricted clone directed against an MAGE-3 epitope from one of our three normal donors. We found no evidence of class I restriction in any $\mathrm{CD} 4{ }^{+}$clone as has been described previously (LeMay et al, 1993; Mitchell et al, 1993; Darrow et al, 1996). Restriction of MAGE epitopes via non-HLA-DR class II molecules as described previously is a more likely explanation for our findings (Schultz et al, 2000; Mandic et al, 2005). None of the $\mathrm{CD} 4{ }^{+}$T-cell clones established in this study secreted interferon- $\gamma$ in response to recipient-derived nonmelanoma cells. Similarly, $\mathrm{CD}^{+}$clones did not lyse normal cells of melanoma patients, suggesting that sibling donor cells capable of mediating graftversus-host reactions did not dominate the cultures. Although in most cases the target antigen could not be identified, the failure to lyse normal patient cells suggested that melanoma-specific or melanoma-associated rather than minor histocompatibility antigens were common targets of clones isolated from normal donors.

Our data do not allow us to assess the use of HLA-identical sibling donor lymphocytes as a starting population for the generation of antimelanoma cells for adoptive therapy. Our $\mathrm{CD}^{+}{ }^{+}$clones proliferated well, but we did not specifically address the question of expansion to therapeutic numbers beyond $10^{9}$ cells in total. Further testing is needed before it can be determined whether a sufficient number of melanoma-reactive cells can be obtained for therapeutic purposes from HLA-identical donors of melanoma sufferers. Nevertheless, our data allow us to conclude that melanoma-reactive precursor cells exist in the peripheral blood of such donors and that the precursors of melanomareactive $\mathrm{CD} 4{ }^{+} \mathrm{T}$ cells are common. Although we cannot be certain of the role of $\mathrm{CD}^{+}$cells in mediating antimelanoma tumour immunity, they may have a number of effects: direct antitumour effector cells, provision of help to $\mathrm{CD}^{+}{ }^{+}$clones with greater direct cytotoxic potential or assistance in the generation of lymphocytes with long-lived memory. They have beneficial therapeutic effects in animal models even when not directly lytic in vitro (Kahn et al, 1991; Shinomiya et al, 1995). If, as described in cytomegalovirus infection (Gamadia et al, 2003), the presence of interferon- $\gamma$ secreting $\mathrm{CD}^{+}$cells is essential for the development of mature and effective CD8 and B-cell responses, infusion of an mixed population of melanoma-reactive cells of both $\mathrm{CD} 4^{+}$and $\mathrm{CD} 8^{+}$ phenotype may assist $\mathrm{CD} 8^{+}$-cell survival and maturation and result in enhancement of a broad antimelanoma immune response.

\section{ACKNOWLEDGEMENTS}

We thank Dr Linda Bendall for helpful discussions and critical review of the manuscript. This work was supported by a grant to DJG and KFB from the NSW Cancer Council.

\section{REFERENCES}

Bay JO, Choufi B, Pomel C, Dauplat J, Durando X, Tournilhac O, Travade P, Plagne R, Blaise D (2000) Potential allogeneic graft-versus-tumor effect in a patient with ovarian cancer. Bone Marrow Transplant 25: $681-682$

Bay JO, Fleury J, Choufi B, Tournilhac O, Vincent C, Bailly C, Dauplat J, Viens P, Faucher C, Blaise D (2002) Allogeneic hematopoietic stem cell transplantation in ovarian carcinoma: results of five patients. Bone Marrow Transplant 30: $95-102$

Boon T, Cerottini JC, Van den Eynde B, van der Bruggen P, Van Pel A (1994) Tumor antigens recognized by T lymphocytes. Annu Rev Immunol 12: 337-365

Chaux P, Vantomme V, Stroobant V, Theilemans K, Corthals J, Luiten R, Eggermont A, Boon T, van der Bruggen P (1999) Identification of MAGE3 epitopes presented by HLA-DR molecules to CD4(+) T lymphocytes. J Exp Med 189: 767 -778

Childs RW (2000) Nonmyeloablative allogeneic peripheral blood stem-cell transplantation as immunotherapy for malignant diseases. Cancer J 6: $179-187$

Childs RW, Clave E, Tisdale J, Plante M, Hensel N, Barrett J (1999) Successful treatment of metastatic renal cell carcinoma with a nonmyeloablative allogeneic peripheral-blood progenitor-cell transplant: evidence for a graft-versus-tumor effect. J Clin Oncol 17: 2044-2049

Coulie PG, Weynants P, Lehmann F, Herman J, Brichard V, Wolfel T, Van Pel A, De Plaen E, Brasseur F, Boon T (1993) Genes coding for tumor antigens recognized by human cytolytic $\mathrm{T}$ lymphocytes. J Immunother 14: $104-109$

Darrow TL, Abdel-Wahab Z, Quinn-Allen MA, Seigler HF (1996) Recognition and lysis of human melanoma by a CD3+, CD4+, CD8T-cell clone restricted by HLA-A2. Cell Immunol 172: $52-59$

Donato ML, Levenback C, Gershenson DM, McMeekin S, Champlin RE (2004) Matched unrelated donor bone marrow transplantation for the treatment of platinum refractory ovarian carcinoma: a case report. Gynecol Oncol 92: 365-367

Dorrschuck A, Schmidt A, Schnurer E, Gluckmann M, Albrecht C, Wolfel C, Lennerz V, Lifke A, Di Natale C, Ranieri E, Gesualdo L, Huber C, Karas M, Wolfel T, Herr W (2004) CD8+ cytotoxic T lymphocytes isolated from allogeneic healthy donors recognize HLA class Ia/Ib-associated renal carcinoma antigens with ubiquitous or restricted tissue expression. Blood 104: 2591 - 2599

Dudley ME, Wunderlich JR, Yang JC, Hwu P, Schwartzentruber DJ, Topalian SL, Sherry RM, Marincola FM, Leitman SF, Seipp CA, RogersFreezer L, Morton KE, Nahvi A, Mavroukakis SA, White DE, Rosenberg SA (2002) A phase I study of nonmyeloablative chemotherapy and adoptive transfer of autologous tumor antigen-specific $\mathrm{T}$ lymphocytes in patients with metastatic melanoma. J Immunother 25: 243-251

Dudley ME, Wunderlich JR, Yang JC, Sherry RM, Topalian SL, Restifo NP, Royal RE, Kammula U, White DE, Mavroukakis SA, Rogers LJ, Gracia GJ, Jones SA, Mangiameli DP, Pelletier MM, Gea-Banacloche J, Robinson MR, Berman DM, Filie AC, Abati A, Rosenberg SA (2005) Adoptive cell transfer therapy following non-myeloablative but lymphodepleting chemotherapy for the treatment of patients with refractory metastatic melanoma. J Clin Oncol 23: 2346-2357

Gamadia LE, Remmerswaal EB, Weel JF, Bemelman F, van Lier RA, Ten Berge IJ (2003) Primary immune responses to human CMV: a critical role for IFN-gamma-producing CD4+ T cells in protection against CMV disease. Blood 101: 2686-2692

Glazyrin AL, Kan-Mitchell J, Mitchell ML (2003) Analysis of in vitro immunization: generation of cytotoxic T-lymphocytes against allogeneic melanoma cells with tumor lysate-loaded or tumor RNA-transfected antigen-presenting cells. Cancer Immunol Immunother 52: 171 - 178

Gottlieb DJ, Prentice HG, Heslop HE, Bello-Fernandez C, Galazka AR, Brenner MK (1989) Effects of recombinant interleukin 2 administration 
on cytotoxic function following high-dose chemo-radiotherapy for haematological malignancy. Blood 74: 2335-2342

Hahn S, Stalder T, Wernli M, Burgin D, Tschopp J, Nagata S, Erb P (1995) Down-modulation of CD4+ T helper type 2 and type 0 cells by $\mathrm{T}$ helper type 1 cells via Fas/Fas-ligand interaction. Eur J Immunol 25: $2679-2685$

Hanel M, Bornhauser M, Muller J, Thiede C, Ehninger G, Kroschinsky F (2003) Evidence for a graft-versus-tumor effect in refractory ovarian cancer. J Cancer Res Clin Oncol 129: $12-16$

Herin M, Lemoine C, Weynants P, Vessiere F, Van Pel A, Knuth A, Devos R, Boon T (1987) Production of stable cytolytic T-cell clones directed against autologous human melanoma. Int J Cancer 39: 390-396

Huang J, El-Gamil M, Dudley ME, Li YF, Rosenberg SA, Robbins PF (2004) $\mathrm{T}$ cells associated with tumor regression recognize frameshifted products of the CDKN2A tumor suppressor gene locus and a mutated HLA class I gene product. J Immunol 172: 6057-6064

Kahn M, Sugawara H, McGowan P, Okuno K, Nagoya S, Hellstrom KE Hellstrom I, Greenberg P (1991) CD4+ T cell clones specific for the human p97 melanoma-associated antigen can eradicate pulmonary metastases from a murine tumor expressing the p97 antigen. J Immunol 146: $3235-3241$

Kobayashi H, Kokubo T, Sato K, Kimura S, Asano K, Takahashi H, Iizuka H, Miyokawa N, Katagiri M (1998) CD4+ T cells from peripheral blood of a melanoma patient recognize peptides derived from nonmutated tyrosinase. Cancer Res 58: 296-301

Kurokawa T, Fischer K, Bertz H, Hoegerle S, Finke J, Mackensen A (2002) In vitro and in vivo characterization of graft-versus-tumor responses in melanoma patients after allogeneic peripheral blood stem cell transplantation. Int J Cancer 101: $52-60$

Lee KH, Wang E, Nielsen MB, Wunderlich J, Migueles S, Connors M, Steinberg SM, Rosenberg SA, Marincola FM (1999) Increased vaccinespecific $\mathrm{T}$ cell frequency after peptide-based vaccination correlates with increased susceptibility to in vitro stimulation but does not lead to tumor regression. J Immunol 163: 6292-6300

LeMay LG, Kan-Mitchell J, Goedegebuure P, Harel W, Mitchell MS (1993) Detection of melanoma-reactive CD4+ HLA-class I-restricted cytotoxic T cell clones with long-term assay and pretreatment of targets with interferon-gamma. Cancer Immunol Immunother 37: 187- 194

Mandic M, Castelli F, Janjic B, Almunia C, Andrade P, Gillet D, Brusic V, Kirkwood JM, Maillere B, Zarour HM (2005) One NY-ESO-1-derived epitope that promiscuously binds to multiple HLA-DR and HLA-DP4 molecules and stimulates autologous $\mathrm{CD} 4+\mathrm{T}$ cells from patients with NY-ESO-1-expressing melanoma. J Immunol 174: 1751 - 1759

Manici S, Sturniolo T, Imro MA, Hammer J, Sinigaglia F, Noppen C, Spagnoli G, Mazzi B, Bellone M, Dellabona P, Protti MP (1999) Melanoma cells present a MAGE-3 epitope to CD4(+) cytotoxic T cells in association with histocompatibility leukocyte antigen DR11. J Exp Med 189: $871-876$

Mitchell MS, Harel W, Kan-Mitchell J, LeMay LG, Goedegebuure P, Huang XQ, Hofman F, Groshen S (1993) Active specific immunotherapy of melanoma with allogeneic cell lysates. Rationale, results, and possible mechanisms of action. Ann NY Acad Sci 690: 153-166

Nolte A, Scheffold C, Slotty J, Huenefeld C, Schultze JL, Grabbe S, Berdel WE, Kienast J (2003) Generation of melanoma-specific cytotoxic T lymphocytes for allogeneic immunotherapy. J Immunother 26: 257-269

Pedrazzoli P, Da Prada GA, Giorgiani G, Schiavo R, Zambelli A, Giraldi E, Landonio G, Locatelli F, Siena S, Della Cuna GR (2002) Allogeneic blood stem cell transplantation after a reduced-intensity, preparative regimen a pilot study in patients with refractory malignancies. Cancer 94: 24092415

Pittet MJ, Speiser DE, Lienard D, Valmori D, Guillaume P, Dutoit V, Rimoldi D, Lejeune F, Cerottini JC, Romero P (2001) Expansion and functional maturation of human tumor antigen-specific CD8+ T cells after vaccination with antigenic peptide. Clin Cancer Res 7: 796s-803s

Robbins PF, El-Gamil M, Li YF, Zeng G, Dudley M, Rosenberg SA (2002) Multiple HLA class II-restricted melanocyte differentiation antigens are recognized by tumor-infiltrating lymphocytes from a patient with melanoma. J Immunol 169: 6036-6047

Schultz ES, Lethe B, Cambiaso CL, Van Snick J, Chaux P, Corthals J, Heirman C, Thielemans K, Boon T, van der Bruggen P (2000) A MAGEA3 peptide presented by HLA-DP4 is recognized on tumor cells by CD4+ cytolytic T lymphocytes. Cancer Res 60: 6272-6275

Shinomiya Y, Harada M, Kurosawa S, Okamoto T, Terao H, Matsuzaki G, Shirakusa T, Nomoto K (1995) Anti-metastatic activity induced by the in vivo activation of purified protein derivative (PPD)-recognizing Th1 type CD4+ T cells. Immunobiology 193: 439-455

Takahashi T, Chapman PB, Yang SY, Hara I, Vijayasaradhi S, Houghton AN (1995) Reactivity of autologous CD4+ T lymphocytes against human melanoma. Evidence for a shared melanoma antigen presented by HLADR15. I Immunol 154: $772-779$

Traversari C, Carbone G, Della Torre G, Bergomi M, Parmiani G, Sensi M (1989) Expression of retrovirus-related, cytotoxic T lymphocyte- and transplantation-defined antigens in $\mathrm{NIH} / 3 \mathrm{~T} 3$ transfectants after a single passage in nude mice. J Immunol 142: 2887-2894

Valmori D, Dutoit V, Lienard D, Rimoldi D, Pittet MJ, Champagne P, Ellefsen K, Sahin U, Speiser D, Lejeune F, Cerottini JC, Romero P (2000) Naturally occurring human lymphocyte antigen-A2 restricted CD8+ Tcell response to the cancer testis antigen NY-ESO-1 in melanoma patients. Cancer Res 60: 4499-4506

Van den Eynde B, Hainaut P, Herin M, Knuth A, Lemoine C, Weynants P, van der Bruggen P, Fauchet R, Boon T (1989) Presence on a human melanoma of multiple antigens recognized by autologous CTL. Int $J$ Cancer 44: 634-640

Zarour HM, Storkus WJ, Brusic V, Williams E, Kirkwood JM (2000) NYESO-1 encodes DRB1 ${ }^{*} 0401$-restricted epitopes recognized by melanomareactive CD4+ T cells. Cancer Res 60: 4946-4952

Zhou J, Dudley ME, Rosenberg SA, Robbins PF (2005) Persistence of multiple tumor-specific T-cell clones is associated with complete tumor regression in a melanoma patient receiving adoptive cell transfer therapy. J Immunother 28: 53-62 